\title{
Complications of Cardiovascular Events in Patients Hospitalized with Influenza-Related Pneumonia
}

\author{
Liang Chen (D) \\ Xiudi $\mathrm{Han}^{2}$ \\ YanLi Li ${ }^{3}$ \\ Chunxiao Zhang ${ }^{4}$ \\ Xiqian Xing ${ }^{5}$ \\ 'Department of Infectious Diseases, \\ Beijing Jishuitan Hospital, 4th Medical \\ College of Peking University, Beijing, \\ People's Republic of China; ${ }^{2}$ Department \\ of Pulmonary and Critical Care Medicine, \\ Qingdao Municipal Hospital, Qingdao \\ City, People's Republic of China; \\ ${ }^{3}$ Department of Infectious Diseases and \\ Clinical Microbiology, Beijing Chao-Yang \\ Hospital, Capital Medical University, \\ Beijing, People's Republic of China; \\ ${ }^{4}$ Department of Pulmonary and Critical \\ Care Medicine, Beijing Huimin Hospital, \\ Beijing, People's Republic of China; \\ ${ }^{5}$ Department of Pulmonary and Critical \\ Care Medicine, The 2nd People's Hospital \\ of Yunnan Province, Kunming City, \\ People's Republic of China
}

This article was published in the following Dove Press journal: Infection and Drug Resistance

Purpose: Influenza virus infections are a key cause of community-acquired pneumonia (CAP). Cardiovascular events (CVEs) are common among CAP and influenza patients, but there have been few population-based studies of influenza-related pneumonia (Flu-p) patients published to date.

Methods: A retrospective analysis of 1191 immunocompetent hospitalized adult Flu-p patients from January 2012 to December 2018 in five teaching hospitals in China was conducted.

Results: A total of $24.6 \%$ (293/1191) of patients developed at least one form of CVE-related complication while hospitalized. In a multivariate logistic regression analysis, hypertension, cerebrovascular disease, coronary artery disease, preexisting heart failure, systolic blood pressure $<90 \mathrm{mmHg}$, respiratory rates $\geq 30$ breaths $/ \mathrm{min}$, a lymphocyte count $<0.8 \times 10^{9} / \mathrm{L}$, $\mathrm{PaO}_{2} / \mathrm{FiO}_{2}<300 \mathrm{mmHg}$, and systemic corticosteroid administration were independently associated with the incidence of CVEs; while early neuraminidase inhibitor treatment and angiotensin converting enzyme inhibitors/angiotensin II receptor blocker treatment were associated with a lower risk of CVEs. After controlling for potential confounding variables, we determined that CVEs were linked to a higher risk of 30-day mortality (OR 3.307, 95\% CI $2.198-4.975, \mathrm{p}<0.001)$ in Flu-p patients.

Conclusion: CVE-related complications are common among hospitalized Flu-p patients and are associated with negative patient outcomes. Clarifying these CVE-related risk factors can aid in their clinical prevention and management.

Keywords: cardiovascular event, influenza-related pneumonia, risk factor, clinical outcome

\section{Introduction}

Community-acquired pneumonia (CAP) remains a major infection-related driver of global morbidity and mortality despite many major medical advances. ${ }^{1}$ In the USA alone, an estimated 5 million adults are affected by CAP each year, resulting in 1.1 million hospital admissions and 60,000 deaths. ${ }^{2}$ A study from Japan estimated the incidence of CAP to be 16.9 per 1000 patient-years in patients above 15 years of age, with a hospitalization rate of 5.3 per 1000 patient-years, and an in-hospital mortality rate of 0.7 per 1000 patient-years. ${ }^{3}$ CAP was the fourth leading cause of death and the most common infectious disease globally in $2019 .^{4}$ In prior work, acute cardiovascular events (CVEs) have been identified as common complications in CAP patients that are associated with higher rates of patient mortality. ${ }^{5}$ A metaanalysis of 25 studies reported a high incidence of cardiac events within 30 days
Correspondence: Liang Chen

Email chenliang1995@sina.com
Infection and Drug Resistance 2021:14 1363-1373

bmit your manuscrip in $\square$ 
with cumulative respective rates of heart failure, arrhythmia, and acute coronary syndrome of 14\% (range: 7-33\%), 5\% (range: $1-11 \%$ ), and 5\% (range: $1-11 \%)^{6}$ One Spanish study of 1405 patients over a 1-year followup period determined that $20 \%$ of patient deaths were attributable to CVEs. ${ }^{7}$ However, prior studies have largely failed to differentiate between the pathogens responsible for individual CAP cases, making the specific etiology of CVEs among CAP patients relatively poorly defined.

Influenza virus causes an estimated $15-20 \%$ of CAP cases, with over 3-5 million cases and 290,000-650,000 deaths globally each year. ${ }^{8}$ Severe influenza infections result in pneumonia in over half of affected patients, ${ }^{9}$ and such influenza-associated pneumonia (Flu-p) can additionally cause multiple organ dysfunction. Time-series analyses have shown that CVE rates are elevated during and immediately following influenza epidemics. ${ }^{10}$ Consistent with this, influenza vaccination is associated with a $36 \%$ reduction in CVE risk in individuals with preexisting cardiovascular disease (risk ratio $0.64,95 \% \mathrm{CI} 0.48-0.86$ ). ${ }^{11}$ This suggests that Flu-p incidence is associated with cardiac disease.

To date, few population-based studies of Flu-p have been conducted. As such, the present multi-center, real-world retrospective analysis was conducted in order to explore CVE incidence, timing, and risk factors in immunocompetent adults hospitalized with community-onset Flu-p, and to assess how CVEs affect Flu-p patient clinical outcomes.

\section{Methods}

\section{Patient Selection}

The medical records of patients that underwent influenza virus nucleic acid testing in the microbiology labs of five tertiary hospitals in China (Supplementary Material 1) between January 1st, 2012 and December 31st, 2018 were reviewed for potential eligibility. All Flu-p patients were eligible for inclusion in this study, but were excluded if they: (i) were not considered to have acquired pneumonia in the community as they had been hospitalized in the past 28 days or suffered from pneumonia $\geq 48 \mathrm{~h}$ following admission; ${ }^{12}$ (ii) were $<14$ years old; or (iii) were immunocompromised, as this could have had an adverse impact on influenza patient outcomes. ${ }^{13}$

\section{Ethics}

The study design was approved by the Ethics Committee of Beijing Jishuitan Hospital (No.201911-15). Given the retrospective nature of the study, the Ethics Committee determined that informed consent was not necessary. This study was in accordance with the declaration of Helsinki.

\section{Study Definitions}

Flu-p patients were defined as those for whom polymerase chain reaction (PCR) analyses of respiratory samples (including sputum, nasal/nasopharyngeal swabs, bronchial aspirates, and bronchoalveolar lavage fluid) were positive for influenza viral RNA, and for whom respiratory symptoms and chest radiographic findings were consistent with newly emergent chest infiltrates. Among patients with prior heart failure, a careful evaluation of clinical and radiological findings as well as of inflammatory markers was performed to differentiate between pneumonia and pulmonary edema. CVEs were defined as any of the following: ( $\mathrm{i}$ ) new or worsening arrhythmias, ie, newly recognized or worsened atrial fibrillation, atrial flutter, supraventricular tachycardia, multifocal atrial tachycardia, ventricular tachycardia, or ventricular fibrillation; ${ }^{14}$ (ii) new or worsening heart failure; (iii) ST elevation or non-ST elevation myocardial infarction (MI); (iv) stroke; (v) new pulmonary embolism (PE). Early neuraminidase inhibitor (NAI) therapy was defined as the administration of NAI agents within two days of symptom onset. ${ }^{15}$ Systemic corticosteroid treatment was the administration of one or more systemic corticosteroid doses while hospitalized. Community-acquired co-infecting respiratory pathogens were those detected using standard microbiological techniques (Supplementary Material 2) within $48 \mathrm{~h}$ following admission. ${ }^{16}$

\section{Data Collection}

A standardized case report form was utilized to extract data from patient medical records including demographic details, patient comorbidities (Supplementary Material 3), patient symptoms, vital signs, laboratory results, radiographic findings at the time of admission, community-acquired co-infecting respiratory pathogens, patient management, and outcomes (including the administration of NAIs, systemic corticosteroids, angiotensin-converting enzyme inhibitors/angiotensin II receptor blockers [ACEIs/ARBs], statins, anticoagulants, antiplatelet agents, and $\beta$-receptor blockers, noninvasive/invasive ventilation, admission to intensive care unit [ICU], and 30-day mortality). Telephone-based follow-up was conducted to identify outcomes for patients hospitalized for $<30$ days.

\section{Statistical Analysis}

Data normality were assessed with Kolmogorov-Smirnov tests. Quantitative data that were normally and non-normally distributed were respectively presented as means \pm standard 


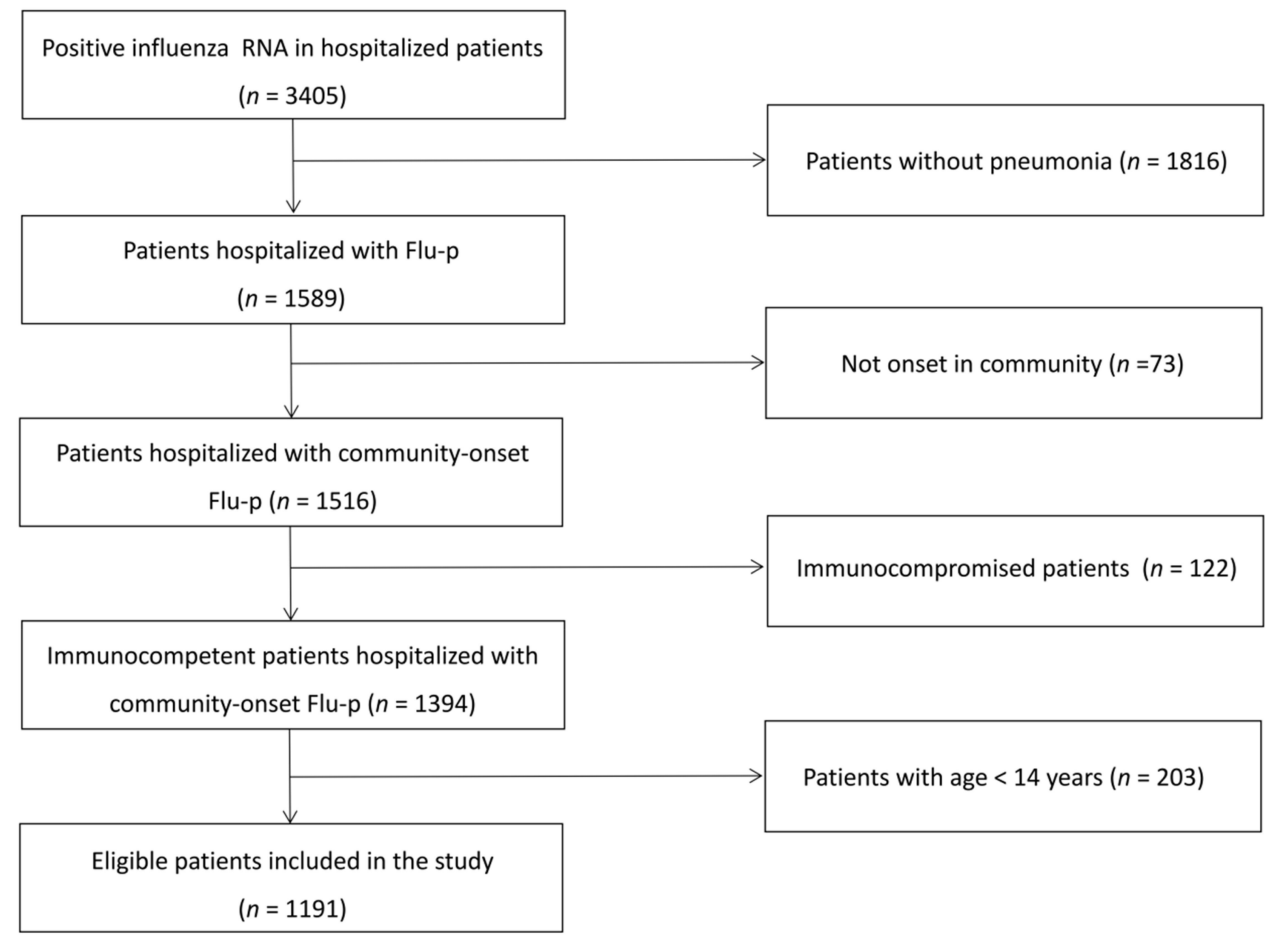

Figure I Patient screening algorithm for Flu-p.

Notes: A total of 3405 patients positive for influenza viral RNA were screened, and II9I eligible Flu-p patients were recruited in this study.

deviation and medians, and were assessed with Student's t-tests and Mann-Whitney $U$-tests. Categorical data were evaluated with Chi-squared and Fisher's exact tests. Our significance threshold was $\mathrm{P}<0.05$.

Patient demographics, baseline clinical features, and treatments were compared between those that did and did not experience CVEs. All variables that yielded a P-value $<0.1$ in univariate analyses were incorporated into a multivariate logistic regression analysis to identify independent predictors of CVEs. Multivariate analyses were also performed to assess the relationship between CVEs and outcomes after adjusting for patient age, sex, time between disease onset and hospital admission, influenza virus type, comorbidities, pregnancy, obesity, smoking history, systemic corticosteroid administration, early NAI therapy, and coinfection as those factors have previously been linked to influenza patient outcomes. SPSS v22.0 was used for all statistical analyses.

\section{Results}

\section{Patient Identification}

In total, 3405 hospitalized patients who tested positive for influenza viral RNA over the course of this study were assessed for eligibility, of whom 1191 were identified as immunocompetent adults with laboratory-confirmed, community-acquired Flu-p and were enrolled in the present study, of whom $64.4 \%$ were infected with influenza A virus $64.4 \%(767 / 1191)$ and $35.6 \%$ were infected with influenza B virus 35.6\% (464/1191) (Figure 1).

\section{Patient Overview}

Flu-p patients in the present study had a median age of $61.0 \mathrm{yrs}$ old (interquartile range [IQR]: 49.0-78.0 yrs) and were 54.5\% male (649/1191). The most common comorbidities in these patients included hypertension $(25.9 \%, 309 / 1191)$, coronary artery disease $(24.6 \%, 293 / 1191)$, and diabetes mellitus $(12.4 \%, 148 / 1191)$, while mental confusion and respiratory rates $\geq 30$ breaths/min were present in 14.0\% (167/1191) and $13.4 \%(159 / 1191)$ of patients at the time of admission, respectively. Just 1.4\% (17/1191) of patients exhibited a systolic blood pressure $<90 \mathrm{mmHg}$, while a lymphocyte count $<$ $0.8 \times 10^{9} / \mathrm{L}$ and $\mathrm{PaO}_{2} / \mathrm{FiO}_{2}<300 \mathrm{mmHg}$ were respectively observed in $45.8 \%(537 / 1173)$ and $47.9 \%(542 / 1132)$ of patients (Table 1).

Coinfections with other community-acquired respiratory pathogens were detected in 34.0\% (405/1191) of patients, with Klebsiella pneumoniae (32.8\%, 133/405), Streptococcus pneumoniae (29.9\%, 121/405), and Staphylococcus aureus $(20.7 \%, 84 / 405)$ being the most common causative pathogens (Supplementary Material 4). 
Table I Comparison of Clinical Features and Outcomes Between Patients with and without CVEs

\begin{tabular}{|c|c|c|c|c|}
\hline Variable & Total $(n=1191)$ & With CVEs $(n=293)$ & Without CVEs $(n=898)$ & $P$ value \\
\hline Age (yrs, median, IQR) & $61.0(49.0-78.0)$ & $65.0(36.0-78.5)$ & $59.0(52.0-77.0)$ & 0.092 \\
\hline Male (n, \%) & $649(54.5)$ & $163(55.6)$ & $486(54.1)$ & 0.652 \\
\hline Flu A infection (n, \%) & $424(35.6)$ & $110(37.5)$ & $314(35.0)$ & 0.424 \\
\hline \multicolumn{5}{|l|}{ Comorbidities (n, \%) } \\
\hline Hypertension $\#$ & $309(25.9)$ & $91(31.1)$ & $218(24.3)$ & 0.021 \\
\hline Coronary artery disease $^{\#}$ & $293(24.6)$ & $124(42.3)$ & $169(18.8)$ & $<0.001$ \\
\hline Preexisting heart failure ${ }^{\#}$ & $39(3.2)$ & $23(7.8)$ & $16(1.8)$ & $<0.001$ \\
\hline Cerebrovascular disease $^{\#}$ & $114(9.6)$ & $40(13.7)$ & $74(8.2)$ & 0.006 \\
\hline Diabetes mellitus & $148(12.4)$ & $44(15.0)$ & $104(11.6)$ & 0.122 \\
\hline COPD $^{\#}$ & $102(8.6)$ & $33(11.3)$ & $69(7.7)$ & 0.057 \\
\hline Asthma & $36(3.0)$ & $12(4.1)$ & $24(2.7)$ & 0.217 \\
\hline Chronic kidney disease $^{\#}$ & $35(2.9)$ & $21(7.2)$ & $14(1.6)$ & $<0.001$ \\
\hline Solid Malignant tumor & $27(2.3)$ & $10(3.4)$ & $17(1.9)$ & 0.129 \\
\hline Pregnancy (n, \%) & $9(0.8)$ & $0(0.0)$ & $9(1.0)$ & 0.183 \\
\hline Obesity (n, \%) & $81(6.8)$ & $23(7.8)$ & $58(6.5)$ & 0.412 \\
\hline Smoking history (n, \%) & $348(29.2)$ & $75(25.6)$ & $273(30.4)$ & 0.116 \\
\hline \multicolumn{5}{|l|}{$\begin{array}{l}\text { Baseline clinical and radiologic features } \\
(\mathrm{n}, \%)\end{array}$} \\
\hline Mental confusion ${ }^{\#}$ & $167(14.0)$ & $103(35.2)$ & $64(7.1)$ & $<0.001$ \\
\hline Respiratory rates $\geq 30$ breaths $/ \mathrm{min}^{\#}$ & $159(13.4)$ & $75(25.6)$ & $84(9.4)$ & $<0.001$ \\
\hline $\mathrm{SBP}<90 \mathrm{mmHg}^{\#}$ & $17(1.4)$ & $8(2.7)$ & $9(1.0)$ & 0.060 \\
\hline Leukocytes $>10 \times 10^{9} / \mathrm{L}^{\#}$ & $309(25.9)$ & $89(30.4)$ & $220(24.5)$ & 0.046 \\
\hline Lymphocytes $<0.8 \times 10^{9} / \mathrm{L}^{\#}$ & $537 / 1173(45.8)$ & $244(83.3)$ & $293 / 880(33.3)$ & $<0.001$ \\
\hline Thrombocytes $>300 \times 10^{9} / \mathrm{L}$ & $53(4.5)$ & $11(3.8)$ & $42(4.7)$ & 0.506 \\
\hline $\mathrm{HB}<100 \mathrm{~g} / \mathrm{L}^{\#}$ & $274(23.0)$ & $117(39.9)$ & $157(17.5)$ & $<0.001$ \\
\hline $\mathrm{ALB}<35 \mathrm{~g} / \mathrm{L}^{\#}$ & $210 / 1131(18.6)$ & $39 / 264(14.8)$ & $171 / 867(19.7)$ & 0.070 \\
\hline $\mathrm{BUN}>7 \mathrm{mmol} / \mathrm{L}^{\#}$ & $489 / 1183(41.3)$ & $193(65.9)$ & $296 / 890(33.3)$ & $<0.001$ \\
\hline BG $>11 \mathrm{mmol} / \mathrm{L}$ & $93 / 1118(8.3)$ & $20 / 260(7.7)$ & $73 / 858(8.5)$ & 0.676 \\
\hline $\mathrm{TG}>1.7 \mathrm{mmol} / \mathrm{L}$ & $107(9.0)$ & $25(8.5)$ & $82(9.1)$ & 0.756 \\
\hline $\mathrm{TC}>5.2 \mathrm{mmol} / \mathrm{L}^{\#}$ & $104(8.7)$ & $33(11.3)$ & $71(7.9)$ & 0.077 \\
\hline $\mathrm{PaO}_{2} / \mathrm{FiO}_{2}<300 \mathrm{mmHg} \mathrm{g}^{\#}$ & $542 / 1132(47.9)$ & $161(54.9)$ & $381 / 839(45.4)$ & 0.005 \\
\hline Multilobar infiltrates $\#$ & $873(73.3)$ & $184(62.8)$ & $689(76.7)$ & $<0.001$ \\
\hline Coinfections ${ }^{\#}$ & $405(34.0)$ & $88(30.0)$ & $317(35.3)$ & 0.098 \\
\hline \multicolumn{5}{|l|}{ Treatment and clinical outcomes } \\
\hline Early NAI therapy $(n, \%)^{\#}$ & $437(36.7)$ & $45(15.4)$ & $392(43.7)$ & $<0.001$ \\
\hline Systemic corticosteroids use $(\mathrm{n}, \%)^{\#}$ & $291(24.4)$ & $149(50.9)$ & $142(15.8)$ & $<0.001$ \\
\hline ACEls/ARBs $(n, \%)^{\#}$ & $478(40.1)$ & $160(54.6)$ & $318(35.4)$ & $<0.001$ \\
\hline Statins (n, \%) & $493(4 \mid .4)$ & $16 \mid(54.9)$ & $332(37.0)$ & $<0.001$ \\
\hline Anticoagulants (n, \%) & $120(10.1)$ & $56(19.1)$ & $64(7.1)$ & $<0.001$ \\
\hline Antiplatelet agents (n, \%) $)^{\#}$ & $349(29.3)$ & $138(47.1)$ & $211(23.5)$ & $<0.001$ \\
\hline$\beta$-receptor blockers (n, \%) & $229(19.2)$ & $81(27.6)$ & $148(16.5)$ & $<0.001$ \\
\hline Noninvasive ventilation $(\mathrm{n}, \%)$ & $306(25.7)$ & $125(42.7)$ & $181(20.2)$ & $<0.001$ \\
\hline Invasive ventilation $(\mathrm{n}, \%)$ & $211(17.7)$ & 117 (39.9) & $94(10.5)$ & $<0.001$ \\
\hline ICU admission (n, \%) & $267(22.4)$ & $122(41.6)$ & $145(16.1)$ & $<0.001$ \\
\hline LOS (days, median, IQR) & $10.0(8.0-14.0)$ & $8.0(6.0-14.0)$ & $10.0(7.0-17.0)$ & 0.023 \\
\hline 30-day mortality (n, \%) & $242(20.3)$ & $|3|(44.7)$ & $111(12.4)$ & $<0.001$ \\
\hline
\end{tabular}

Notes: "Variables cited in the table above were the candidates which were entered into the multivariate logistic regression model. The bolded values are $\mathrm{p}$-values $<0.05$, which represented significant differences between patients with and without CVEs.

Abbreviations: CVEs, cardiovascular events; IQR, interquartile range; COPD, chronic obstructive pulmonary disease; SBP, systolic blood pressure; HB, hemoglobin; BG, blood glucose; ALB, albumin; BUN, blood urea nitrogen; TG, triglyceride; TC, total cholesterol; $\mathrm{PaO}_{2} / \mathrm{FiO}_{2}$, arterial pressure of oxygen/fraction of inspiration oxygen; $\mathrm{NAI}$, neuraminidase inhibitor; ACEls/ARBs, angiotensin converting enzyme inhibitors/angiotensin II receptor blockers; ICU, intensive care unit; LOS, length of stay in hospital. 


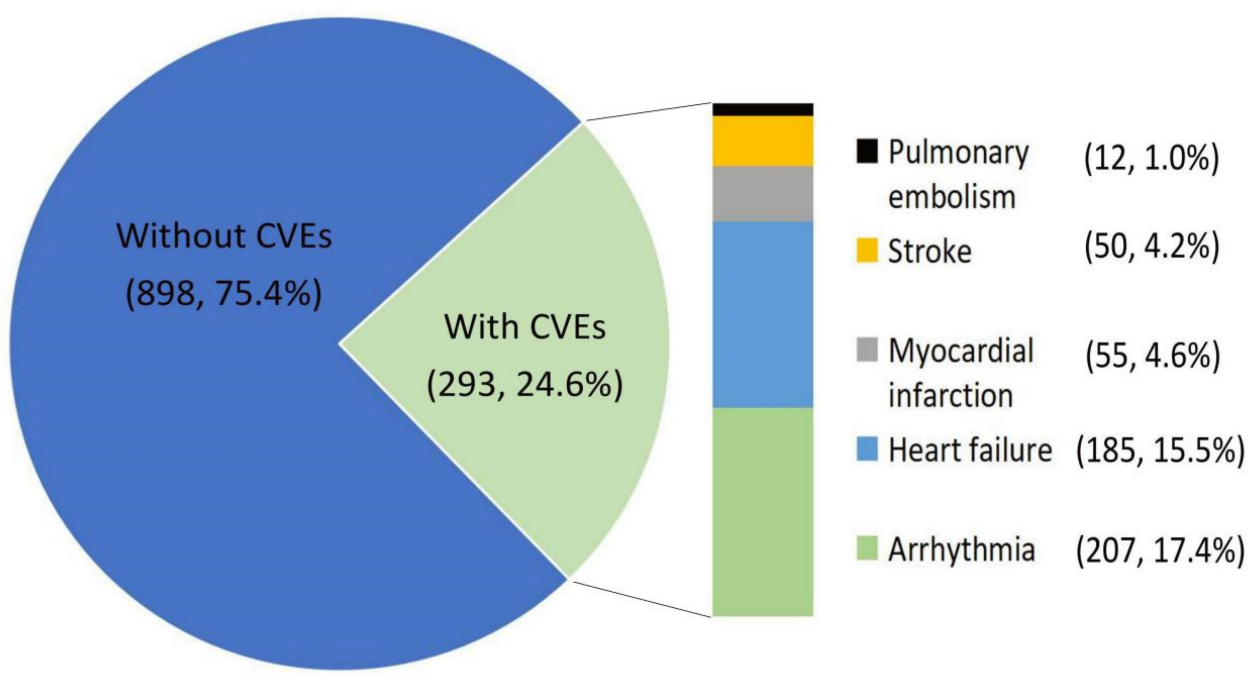

Figure 2 Frequency and type of CVEs occurred in Flu-p patients.

Notes: At least one type of CVE occurred in $24.6 \%$ of Flu-p patients, with the most common CVEs being arrhythmia (I7.4\%), heart failure (I5.5\%), myocardial infarction (4.6\%), stroke (4.2\%), and pulmonary embolism (1.0\%).

Early NAI therapy was performed in $36.7 \%$ (437/ 1191) of patients, whereas $24.4 \%$ were treated with systemic corticosteroids. ACEIs/ARBs, statins, anticoagulants, antiplatelet agents, and $\beta$-receptor blockers were administrated to $40.1 \%$ (478/1191), $41.4 \%$ (493/ $1191), \quad 10.1 \% \quad(120 / 1191), 29.3 \% \quad(349 / 1191)$, and $19.2 \%(229 / 1191)$ of patients, respectively. Noninvasive and invasive ventilation were conducted for $25.7 \% \quad(306 / 1191)$ and $17.7 \% \quad(211 / 1191)$ of patients, respectively. Of these patients, $22.4 \%$ (267/ 1191) were admitted to ICU, and the all-cause 30-day mortality rate for this patient cohort was $20.3 \%$ (242/ 1191) (Table 1).

\section{Type, Incidence, and Timing of CVEs in Flu-p Patients}

At least one type of CVE occurred in 24.6\% (293/1191) of Flu-p patients, with the most common CVEs being arrhythmia (17.4\%, 207/1191), heart failure (15.5\%, 185/ 1191), myocardial infarction $(4.6 \%, 55 / 1191)$, stroke (4.2\%, 50/1191), and pulmonary embolism $(1.0 \%, 12 /$ 1191) (Figure 2).

The median times between admission and the incidence of each CVE type were as follows: arrhythmia (2.0 days, IQR: 1.0-5.0 days), heart failure (3.0 days, IQR:2.0-4.0 days), MI (2.0 days, IQR: 1.0-3.0 days), stroke (7.0 days, 5.0-8.0 days), and PE (11.5 days, IQR: 10.0-14.0 days) (Figure 3).

\section{Risk Factors Associated with CVE Incidence in Flu-p Patients}

Relative to patients without CVEs, those with CVEs were more likely to suffer from hypertention $(31.1 \%$ vs $24.3 \%$, $\mathrm{p}=0.021)$, coronary artery disease $(42.3 \%$ vs $18.8 \%, \mathrm{p}<$ $0.001)$, preexisting heart failure $(7.8 \%$ vs $1.8 \%, p<0.001)$, cerebrovascular disease $(13.7 \%$ vs $8.2 \%, \mathrm{p}=0.006)$, and chronic kidney disease $(7.2 \%$ vs $1.6 \%, p<0.001)$. Mental confusion $(35.2 \%$ vs $7.1 \%, \mathrm{p}<0.001)$, respiratory rates $\geq$ 30 breaths $/ \min (25.6 \%$ vs $9.4 \%, \mathrm{p}<0.001)$, leukocyte counts $>10 \times 10^{9} / \mathrm{L}(30.4 \%$ vs $24.5, \mathrm{p}=0.046)$, lymphocytes $<0.8 \times 10^{9} / \mathrm{L}(83.3 \%$ vs $33.3 \%, \mathrm{p}<0.001)$, hemoglobin (HB) levels $<100 \mathrm{~g} / \mathrm{L}(39.9 \%$ vs $17.5 \%, \mathrm{p}<0.001)$, blood urea nitrogen $(\mathrm{BUN})>7 \mathrm{mmol} / \mathrm{L}(65.9 \%$ vs $33.3 \%$, $\mathrm{p}<0.001)$, and $\mathrm{PaO}_{2} / \mathrm{FiO}_{2}<300 \mathrm{mmHg}(54.9 \%$ vs 45.4 , $\mathrm{p}=0.005$ ) at time of admission were more frequently observed in patients with CVEs than in patients without CVEs. Patients with CVEs were more likely to be treated with systemic corticosteroids $(50.9 \%$ vs $15.8 \%$, p < $0.001)$, ACEIs/ARBs (54.6\% vs $35.4 \%, \mathrm{p}<0.001)$, statins $(54.9 \%$ vs $37.0 \%$, bp $<0.001)$, anticoagulants $(19.1 \%$ vs $7.1 \%, \mathrm{p}<0.001)$, and $\beta$-receptor blockers $(27.6 \%$ vs $16.5 \%, \mathrm{p}<0.001$ ), and were less likely to have undergone early NAI therapy $(15.4 \%$ vs $43.7 \%, p<0.001)$ (Table 1$)$.

Multivariate logistic regression analyses revealed hypertension (OR 4.038, 95\% CI 2.023-8.062, p < 0.001), cerebrovascular disease (OR 4.716, 95\% CI 2.175-10.229, $\mathrm{p}<0.001$ ), coronary artery disease (OR 5.554, 95\% CI 


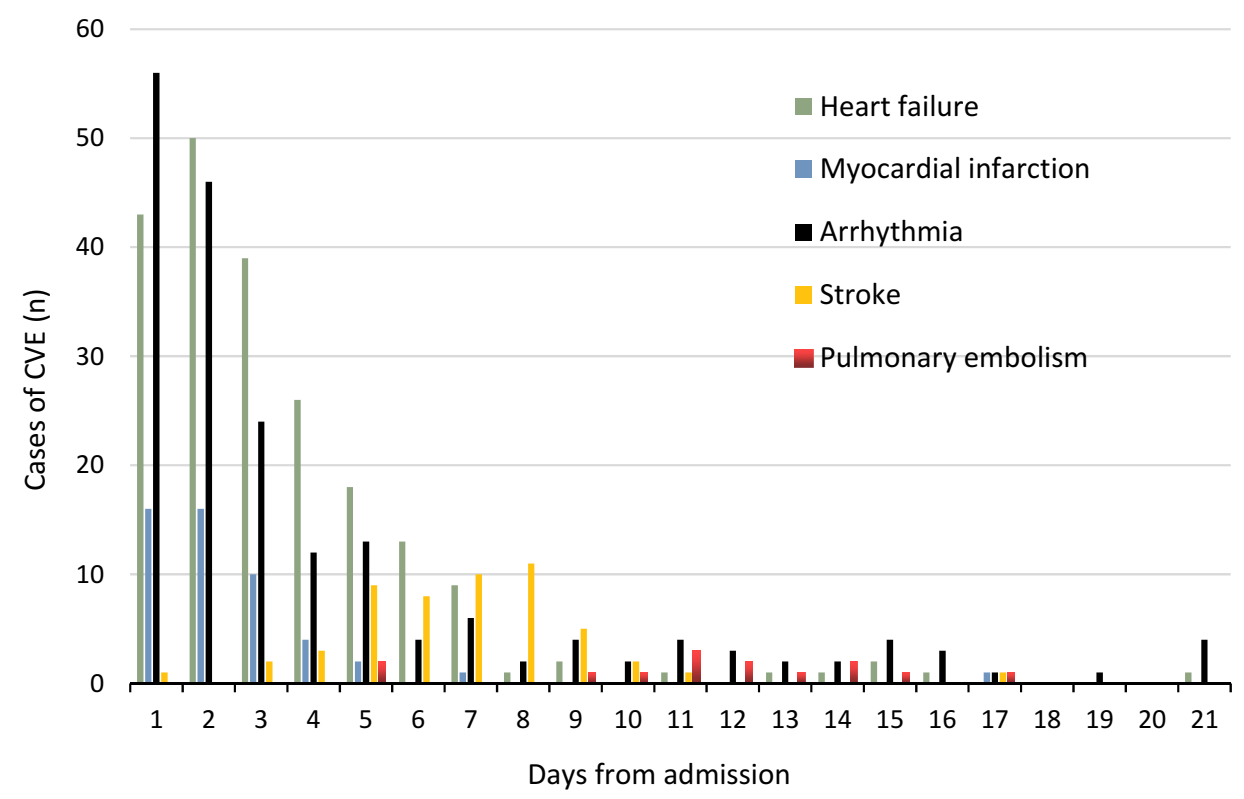

Figure 3 Timing of CVEs in Flu-p patients.

Notes: The median times between admission and the incidence of each CVE type were as follows: arrhythmia ( 2.0 days, IQR: I.0-5.0 days), heart failure (3.0 days, IQR:2.0-4.0 days), MI (2.0 days, IQR: I.0-3.0 days), stroke (7.0 days, 5.0-8.0 days), and PE (II.5 days, IQR: I0.0-I4.0 days).

2.447-12.604, $\mathrm{p}<0.001)$, preexisting heart failure (OR 5.634, 95\% CI 1.919-16.538, $\mathrm{p}=0.002)$, systolic blood pressure $<90 \mathrm{mmHg}(\mathrm{OR} 6.178,95 \%$ CI 1.626-23.476, $\mathrm{p}=$ 0.008 ), a respiratory rate $\geq 30$ breaths $/ \mathrm{min}$ (OR 6.870, 95\% CI 3.803-12.409, p < 0.001), a lymphocyte count < $0.8 \times 10^{9} / \mathrm{L}(\mathrm{OR} 7.604,95 \%$ CI 4.499-12.853, $\mathrm{p}<0.001)$, $\mathrm{PaO}_{2} / \mathrm{FiO}_{2}<300 \mathrm{mmHg}(\mathrm{OR} 2.057,95 \%$ CI 1.348-3.140, $\mathrm{p}=0.001)$, and systemic corticosteroid administration (OR $3.708,95 \%$ CI $2.306-5.962, \mathrm{p}<0.001)$ to be independently associated with CVE incidence; while early NAI treatment (OR 0.402, 95\% CI 0.158-0.780, p < 0.001) and ACEIs/ ARBs treatment (OR 0.383, 95\% CI 0.153-0.960, p = 0.041 ) were associated with a lower risk of CVE (Figure 4).

\section{The Relationship Between CVEs and Flu-p Patient Outcomes}

In univariate analyses, CVEs were related to higher rates of 30day Flu-p patient mortality (OR 5.733, 95\% CI 4.230-7.772, $\mathrm{p}<0.001$ ), with CVE-specific odds ratios for arrhythmia, heart failure, MI, stroke, and PE of 4.448 (95\% CI 3.215-6.154, p < 0.001), 5.482 (95\% CI 3.917-7.672, p < 0.001), 16.872 (95\% CI 8.739-32.577, $\mathrm{p}<0.001), 7.881$ (95\% CI 4.340-14.312, $\mathrm{p}<$ $0.001)$, and 3.996 (95\% CI 1.277-12.501, p = 0.012), respectively (Table 2).

Following adjustment for age, sex, comorbidities, obesity, pregnancy, smoking history, early NAI treatment, and systemic corticosteroid administration, CVEs were linked to an elevated risk of 30-day mortality (OR 3.307, 95\% CI 2.198-4.975, p $<0.001)$ in Flu-p patients. Similarly, arrhythmia (OR 2.465, 95\% CI 1.586-3.830, p < 0.001), heart failure (OR 2.997, 95\% CI 1.938-4.637, $\mathrm{p}<0.001$ ), MI (OR 15.017, 95\% CI 6.857-32.887, p < 0.001), stroke (OR 4.507, 95\% CI 1.790-11.346, $\mathrm{p}=0.001)$, and PE (OR $4.557,95 \%$ CI $1.051-19.755, \mathrm{p}=0.043)$ were all associated with higher 30-day mortality risk (Table 2).

Comparable associations were also observed with respect to the relationships between CVEs and invasive ventilation (Supplementary Material 5) and ICU admission (Supplementary Material 6).

Relative to patients that did not experience CVEs, the survival rates of patients that experienced one (Hazard ratio [HR] 2.059, 95\% CI 1.355-3.130, p $=0.001$ ), two (HR 2.727, 95\% CI 1.893-3.929, p < 0.001), and three types of CVEs (HR 5.832, 95\% CI 3.600-9.446, p < 0.001 ) within 30 days following admission were significantly lower (Figure 5).

\section{Discussion}

Cardiovascular complications affected almost one-quarter of the Flu-p patients in the present multi-center real-world study, confirming the strong relationship between these two conditions. Consistent with prior reports regarding CAP and influenza infections, the most common CVEs 


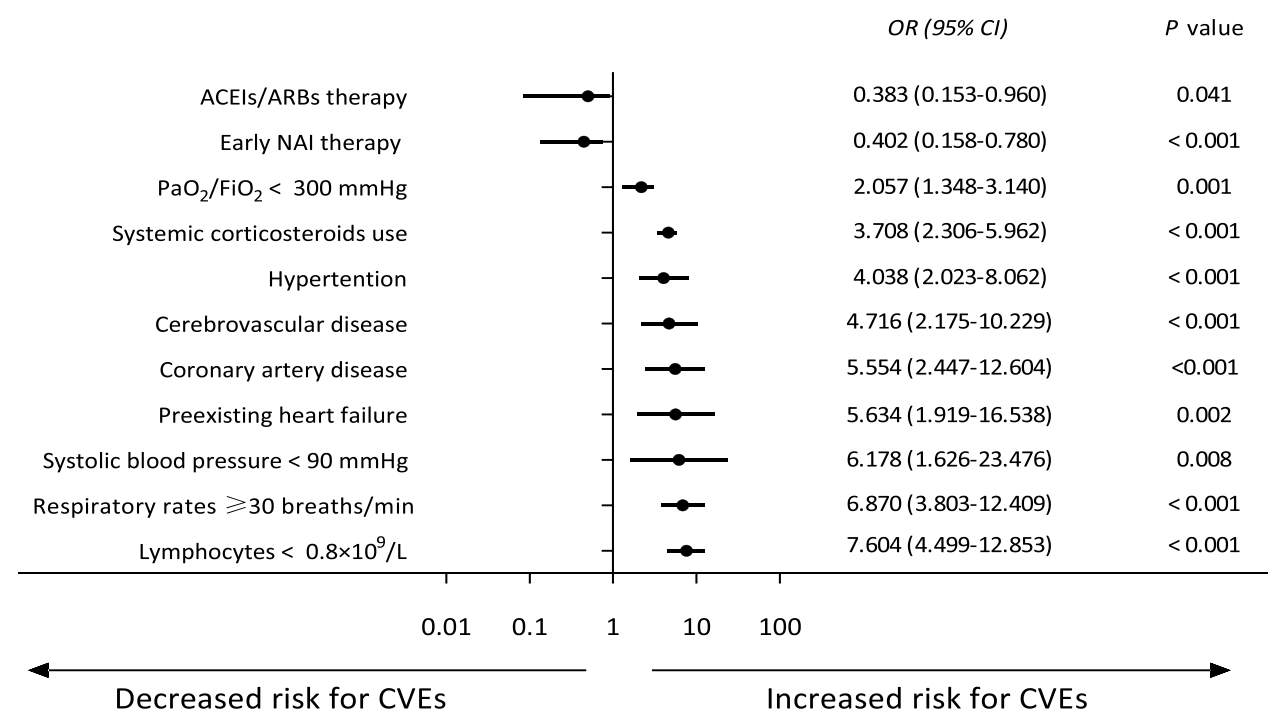

Figure 4 Risk factors for the incidence of CVEs in Flu-p patients.

Notes: Multivariate logistic regression analysis revealed that hypertension, coronary artery disease, chronic heart failure, cerebrovascular disease, respiratory rate $\geq 30$ breaths $/ \mathrm{min}$, systolic blood pressure $<90 \mathrm{mmHg}$, lymphocytes $<0.8 \times 10^{9} / \mathrm{L}, \mathrm{PaO}_{2} / \mathrm{FiO}_{2}<300 \mathrm{mmHg}$ at admission, and systemic corticosteroid administration were associated with an increased risk of CVEs, while early NAI administration and ACEls/ARBs treatment were related to a decreased risk of CVEs.

observed in patients in the present cohort were heart failure and arrhythmia, followed by MI and stroke, with PE being a relatively rare occurrence..$^{5-7,14,15,17}$ We also found that arrhythmia, heart failure, and MI primarily occurred within 1-3 days post-admission, while stroke typically occurred within one week, and PE most often occurred during the second week. These temporal differences in CVE incidence may be relevant to clinicians who can take staged preventative action to reduce patient risk during these different periods.

A number of different mechanisms associated with systemic responses to the influenza virus may explain the high incidence of CVEs among Flu-p patients. ${ }^{18}$ Myocardial function can be depressed in response to systemic inflammation, which can also increase left ventricular afterload. Hypoxemia suppresses myocardial oxygen delivery and increases both

Table 2 The Impact of CVEs on the 30-Day Mortality of Flu-p Patients

\begin{tabular}{|c|c|c|c|c|c|c|}
\hline \multirow[t]{2}{*}{ Type of CVE } & \multirow[t]{2}{*}{ Population } & \multirow[t]{2}{*}{ Cases (n, \%) } & \multicolumn{2}{|c|}{ Univariate Logistic Analysis } & \multicolumn{2}{|c|}{ Multivariate Logistic Analysis } \\
\hline & & & OR (95\% CI) & $\boldsymbol{P}$ & OR $(95 \% \mathrm{CI})$ & $\boldsymbol{P}$ \\
\hline Total CVEs & $\begin{array}{l}\text { Without } \\
\text { With }\end{array}$ & $\begin{array}{l}\text { II I/898 (I2.4) } \\
\text { I3I/293 (44.7) }\end{array}$ & $\begin{array}{c}\text { Ref } \\
5.733(4.230-7.772)\end{array}$ & $<0.001$ & $\begin{array}{c}\text { Ref } \\
3.307(2.198-4.975)\end{array}$ & $<0.001$ \\
\hline Arrhythmia & $\begin{array}{l}\text { Without } \\
\text { With }\end{array}$ & $\begin{array}{l}150 / 984(15.2) \\
92 / 207(44.4)\end{array}$ & $\begin{array}{c}\text { Ref } \\
4.448(3.215-6.154)\end{array}$ & $<0.001$ & $\begin{array}{c}\text { Ref } \\
2.465(1.586-3.830)\end{array}$ & $<0.001$ \\
\hline Heart failure & $\begin{array}{l}\text { Without } \\
\text { With }\end{array}$ & $\begin{array}{c}151 / 1006(15.0) \\
91 / 185(49.2)\end{array}$ & $\begin{array}{c}\text { Ref } \\
5.482(3.917-7.672)\end{array}$ & $<0.001$ & $\begin{array}{c}\text { Ref } \\
2.997(1.938-4.637)\end{array}$ & $<0.001$ \\
\hline Myocardial infarction & $\begin{array}{l}\text { Without } \\
\text { With }\end{array}$ & $\begin{array}{c}199 / 1136(17.5) \\
43 / 55(78.2)\end{array}$ & $\begin{array}{c}\text { Ref } \\
16.872(8.739-32.577)\end{array}$ & $<0.001$ & $\begin{array}{c}\text { Ref } \\
15.017(6.857-32.887)\end{array}$ & $<0.001$ \\
\hline Stroke & $\begin{array}{l}\text { Without } \\
\text { With }\end{array}$ & $\begin{array}{c}210 / 114 \mid(18.4) \\
32 / 50(64.0)\end{array}$ & $\begin{array}{c}\text { Ref } \\
7.881(4.340-14.312)\end{array}$ & $<0.001$ & $\begin{array}{c}\text { Ref } \\
4.507(1.790-\mid 1.346)\end{array}$ & 0.001 \\
\hline Pulmonary embolism & $\begin{array}{l}\text { Without } \\
\text { With }\end{array}$ & $\begin{array}{c}236 / 1179(20.0) \\
6 / 12(50.0)\end{array}$ & $\begin{array}{c}\text { Ref } \\
3.996(1.277-\mid 2.50 I)\end{array}$ & 0.012 & $\begin{array}{c}\text { Ref } \\
4.557(1.05 \mathrm{I}-19.755)\end{array}$ & 0.043 \\
\hline
\end{tabular}

Abbreviations: $\mathrm{OR}$, odd ratio; $\mathrm{Cl}$, confidence interval. 


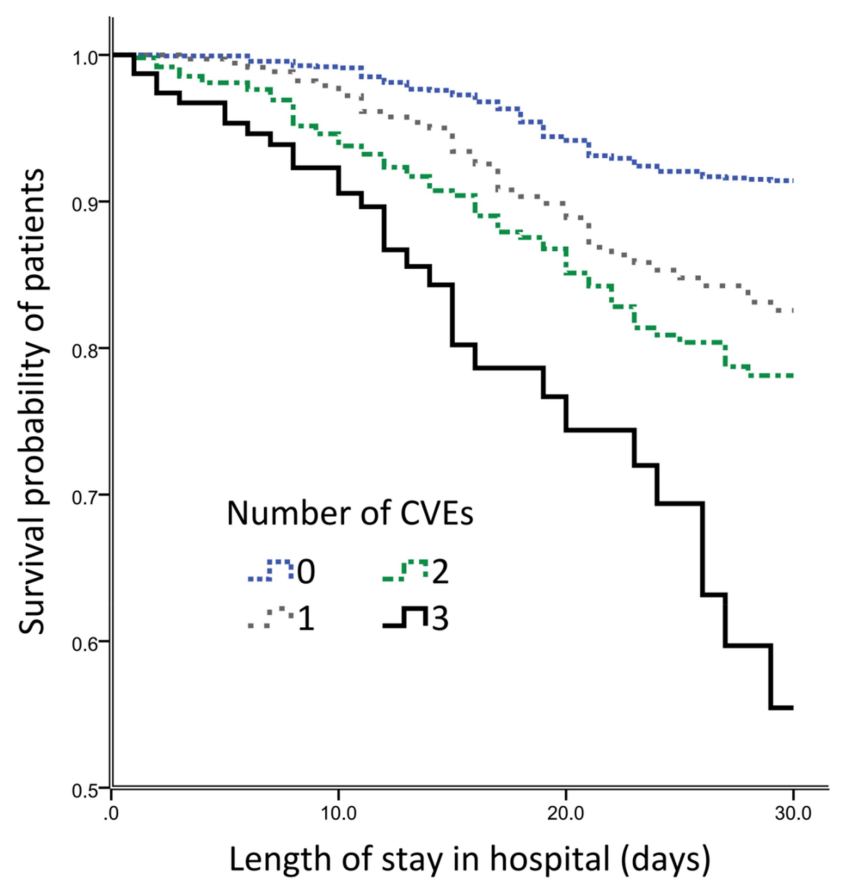

Figure 5 The impact of CVEs numbers on the 30-day mortality of Flu-p patients. Notes: Relative to patients that did not experience CVEs, the survival rates of patients that experienced one, two, or three types of CVEs within 30 days following admission were significantly lower.

pulmonary arterial pressure and right ventricular afterload. Tachycardia results in a rise in myocardial oxygen requirements and shortened diastole, resulting in a net negative shift in further myocardial dysfunction. This mismatch between myocardial oxygen supply and demand leads to post-infectious myocardial injury. ${ }^{19}$ Direct virus-induced myocardial inflammation can also contribute to this process. The influenza virus can also promote prothrombotic alterations in the blood and endothelial tissues, reducing atherosclerotic plaque stability and increasing the odds of coronary thrombosis.

CVE incidence in Flu-p patients is linked to underlying disease severity and the incidence of any comorbidities. Acute decompensation is more likely to occur in patients with preexisting cardiovascular or cerebrovascular disease suffering from acute disease-related inflammation. Severe Flu-p is characterized by impaired pulmonary function and diffuse alveolar damage, ${ }^{20}$ with pulmonary damage ultimately inducing tachypnea and reduced $\mathrm{PaO}_{2} / \mathrm{FiO}_{2}$. Hypotension is most often secondary to severe infection, and is indicative of serious hemodynamic abnormalities. ${ }^{21}$ In contrast with previous reports regarding $\mathrm{CAP},{ }^{5-7}$ age was not an independent predictor of CVEs in our present study. One possible explanation for this discrepancy is that more than $50 \%$ of severe patients with A (H1N1) pmd09 infections were young patients. ${ }^{22}$
Lymphocytopenia occurs in 30-100\% of severe influenza cases ${ }^{22,23}$ and is linked to the apoptotic death of CD4 + and CD8+ T cells, in turn delaying viral clearance. ${ }^{24,25}$ These lymphocytes can also be depleted from circulation when they are recruited into the lungs or other organs in response $t$ viral infection. ${ }^{26}$ Pulmonary lymphocyte accumulation can result in increasingly severe localized inflammation and tissue damage. Lymphocytopenia has previously been identified as a predictor of influenza disease severity, thereby increasing the risk of CVEs. ${ }^{22,27,28}$

This study is the first cohort study to our knowledge to have evaluated the relationship between ACEI/ARB used and influenza severity. Angiotensin-converting enzyme (ACE) is expressed on pulmonary endothelial cells wherein functions by converting angiotensin I to angiotensin II (Ang II). ${ }^{29}$ Ang II can, in turn, activate the pulmonary AT1a receptor, thereby inducing the contraction of bronchial smooth muscle, increasing vascular permeability within the lung, promoting the proliferation of pulmonary fibroblasts, and driving alveolar epithelial cell apoptosis, thereby contributing to acute lung injury and severe Flu-p symptoms. ${ }^{30}$ Ang II can additionally induce vasoconstriction and circulation resistance, elevating the risk of CVE incidence. Huang et $\mathrm{al}^{31}$ observed a relationship between severe H7N9 influenza infectionrelated mortality and plasma Ang II levels. Zou et $\mathrm{al}^{32}$ also found severe H5N1 avian influenza infections to be associated with elevated serum Ang II levels. ACEIs can reduce Ang II production and thereby prevent severe pulmonary injury and lower the risk of CVE incidence. A combination of plasma exchange therapy and ACEI treatment were sufficient to improve the condition of a patient suffering from scleroderma renal crisis and influenza $B$ virus-triggered thrombotic microangiopathy. ${ }^{33}$ In another case report, the aggressive treatment of a woman suffering from H1N1 influenza and severe acute left ventricular failure resulted in improvements in symptoms and left ventricular function. ${ }^{34}$ Angiotensin II receptor blockers (ARBs) can selectively bind to AT1 receptors expressed in the vascular smooth muscle to selectively inhibit Ang II, thereby lowering blood pressure and preventing major CVE incidence. While we found that more CVE patients were treated with ACEIs/ARBs, the directionality of the relationship between ACEIs/ARBs and the incidence of CVEs changed following adjustment for confounders. Cardiac complications are also prevalent $(\sim 60 \%)$ in those suffering from coronavirus disease 2019 (COVID-19). ${ }^{35}$ In a murine model, an increased level in angiotensin II ultimately increases pulmonary vascular permeability, leading to pulmonary edema and reduced lung function. ${ }^{36}$ Treatment with recombinant ACE237 and losartan 
mitigated the degree of lung injury. ${ }^{37}$ Given that severe influenza and COVID-19 share certain pathological similarities, our results provide a valuable reference to the treatment of COVID-19.

In theory, certain medications including statins, $\beta$-receptor blockers, anticoagulants, and antiplatelet drugs may prevent a subset of cardiovascular complications. $\beta$-receptor blockers, for example, can lower tachyarrhythmia risk but may elevate the chances of heart failure, ${ }^{38}$ while anticoagulants and antiplatelet agents can reduce myocardial ischemia, cerebral infarction, and PE risk while increasing the chances of cerebral hemorrhage and failing to prevent arrhythmia. ${ }^{39}$ Such variability may explain the lack of any observed relationship between these medications and CVEs in the present analysis.

Several studies have confirmed that NAI treatment is associated with lower complication and mortality rates among influenza patients. ${ }^{40}$ In contrast, systemic systemic corticosteroid use can inhibit the function of the immune system and thereby increase the risk of severe nosocomial pneumonia, inflammation, and consequent CVEs. ${ }^{41}$ Although the antiinflammatory effects and impaired platelet activation associated with corticosteroid treatment may be protective and associated with a lower rate of MI in some specific populations such as pneumonia patients with chronic obstructive pulmonary disease, ${ }^{42}$ these conclusion cannot be generalized, particularly in patients with influenza-associated pneumonia. Controlled interventional trials will be necessary to confirm whether such a relationship exists.

Prior studies have shown cardiac complications to be associated with worse outcomes among CAP and influenza patients, consistent with the results of the present study. ${ }^{5,6,17}$ We additionally found that different types and numbers of CVEs were associated with differences in patient clinical outcomes. Mortality rates were highest among patients who suffered from MIs, and the risk of death rose with increasing numbers of CVEs.

There are certain limitations to the present study that should be considered. For one, this was a retrospective study that was thus susceptible to selection bias despite our large sample size. Nucleic acid testing, for example, was performed in accordance with the subjective judgment of attending physicians such that not all eligible patients may have undergone such testing. We were also unable to access vaccination-related data or other missing information owing to the retrospective nature of this study, limiting the accuracy of these results. Lastly, certain mild or asymptomatic CVEs may have been ignored or not recorded in patient medical records such that actual CVE rates may be higher than those reported herein. However, even in a prospective study it would be impracticable to conduct continuous ECG monitoring for all patients.

\section{Conclusions}

In summary, we found that CVE complications were common among hospitalized Flu-p patients and were associated with poor patient outcomes. A better understanding of the types, timing, and risk factors for cardiac complications will guide clinicians in the care of CVEs and the management of Flu-p patients.

\section{Ethical Approval}

The study design was approved by the Ethics Committee of Beijing Jishuitan Hospital (No. 201,911-15). Given the retrospective nature of the study, the Ethics Committee determined that an informed consent was not required. The data of the patients used in the study were anonymized or maintained with confidentiality. The patient data accessed complied with relevant data protection and privacy regulations.

\section{Acknowledgments}

The authors would like to express their gratitude to BMCSCI (http://www.bmcscience.com/) for the expert linguistic services provided.

\section{Author Contributions}

All authors made a significant contribution to the work reported, whether that is in the conception, study design, execution, acquisition of data, analysis and interpretation, or in all these areas; took part in drafting, revising or critically reviewing the article; gave final approval of the version to be published; have agreed on the journal to which the article has been submitted; and agree to be accountable for all aspects of the work.

\section{Funding}

This study was funded by Beijing JST research (ZR201921). The funding agencies had no role in the study design, data collection and analysis, decision to publish or preparation of the manuscript.

\section{Disclosure}

The authors declare they have no conflicts of interest for this work. 


\section{References}

1. Lanks CW, Musani AI, Hsia DW. Community-acquired pneumonia and hospital-acquired pneumonia. Med Clin North Am. 2019;103 (3):487-501. doi:10.1016/j.mcna.2018.12.008

2. Corrales-Medina VF, Musher DM, Shachkina S, Chirinos JA. Acute pneumonia and the cardiovascular system. Lancet. 2013;381 (9865):496-505. doi:10.1016/S0140-6736(12)61266-5

3. Morimoto K, Suzuki M, Ishifuji T, et al. The burden and etiology of community-onset pneumonia in the aging Japanese population: a multicenter prospective study. PLoS One. 2015;10(3):e0122247. doi:10.1371/journal.pone. 0122247

4. Collaborators GBDV. Five insights from the Global Burden of Disease Study 2019. Lancet. 2020;396(10258):1135-1159. doi:10.1016/S0140-6736(20)31404-5

5. Aliberti S, Ramirez JA. Cardiac diseases complicating community-acquired pneumonia. Curr Opin Infect Dis. 2014;27 (3):295-301. doi:10.1097/QCO.0000000000000055

6. Corrales-Medina VF, Suh KN, Rose G, et al. Cardiac complications in patients with community-acquired pneumonia: a systematic review and meta-analysis of observational studies. PLoS Med. 2011;8(6): e1001048. doi:10.1371/journal.pmed.1001048

7. Griffin AT, Wiemken TL, Arnold FW. Risk factors for cardiovascular events in hospitalized patients with community-acquired pneumonia. Int J Infect Dis. 2013;17(12):e1125-1129. doi:10.1016/j.ijid.2013.07.005

8. Lozano R, Naghavi M, Foreman K, et al. Global and regional mortality from 235 causes of death for 20 age groups in 1990 and 2010: a systematic analysis for the Global Burden of Disease Study 2010. Lancet. 2012;380 (9859):2095-2128. doi:10.1016/S0140-6736(12)61728-0

9. Chen L, Han X, Bai L, Zhang J. Clinical characteristics and outcomes in adult patients hospitalized with influenza, respiratory syncytial virus and human metapneumovirus infections. Expert Rev Anti Infect Ther. 2020;1-10. doi:10.1080/14787210.2021.1846520

10. Nguyen JL, Yang W, Ito K, Matte TD, Shaman J, Kinney PL. Seasonal influenza infections and cardiovascular disease mortality. JAMA Cardiol. 2016;1(3):274-281. doi:10.1001/jamacardio.2016.0433

11. Udell JA, Zawi R, Bhatt DL, et al. Association between influenza vaccination and cardiovascular outcomes in high-risk patients: a meta-analysis. JAMA. 2013;310(16):1711-1720. doi:10.1001/jama.2013.279206

12. Chen L, Zhou F, Li H, et al. Disease characteristics and management of hospitalised adolescents and adults with community-acquired pneumonia in China: a retrospective multicentre survey. BMJ Open. 2018;8(2):e018709. doi:10.1136/bmjopen-2017-018709

13. Collins JP, Campbell AP, Openo K, et al. Outcomes of immunocompromised adults hospitalized with laboratory-confirmed influenza in the United States, 2011-2015. Clin Infect Dis. 2020;70 (10):2121-2130. doi:10.1093/cid/ciz638

14. Corrales-Medina VF, Musher DM, Wells GA, Chirinos JA, Chen L, Fine MJ. Cardiac complications in patients with community-acquired pneumonia: incidence, timing, risk factors, and association with short-term mortality. Circulation. 2012;125(6):773-781. doi:10.1161/CIRCULATIONAHA.111.040766

15. Katzen J, Kohn R, Houk JL, Ison MG. Early oseltamivir after hospital admission is associated with shortened hospitalization: a 5-year analysis of oseltamivir timing and clinical outcomes. Clin Infect Dis. 2019;69(1):52-58. doi:10.1093/cid/ciy860

16. Jain S, Self WH, Wunderink RG, et al. Community-acquired pneumonia requiring hospitalization among U.S. adults. $N$ Engl $J$ Med. 2015;373(5):415-427. doi:10.1056/NEJMoa1500245

17. Chow EJ, Rolfes MA, O'Halloran A, et al. Acute cardiovascular events associated with influenza in hospitalized adults: a Cross-sectional Study. Ann Intern Med. 2020;173(8):605-613. doi:10.7326/M20-1509

18. Golia E, Limongelli G, Natale F, et al. Inflammation and cardiovascular disease: from pathogenesis to therapeutic target. Curr Atheroscler Rep. 2014;16(9):435. doi:10.1007/s11883-014-0435-z
19. Putot A, Chague F, Manckoundia P, Cottin Y, Zeller M. Postinfectious myocardial infarction: new insights for improved screening. J Clin Med. 2019;8(6):827. doi:10.3390/jcm8060827

20. Herfst S, van den Brand JM, Schrauwen EJ, et al. Pandemic 2009 H1N1 influenza virus causes diffuse alveolar damage in cynomolgus macaques. Vet Pathol. 2010;47(6):1040-1047. doi:10.1177/0300985810374836

21. Demiselle J, Fage N, Radermacher P, Asfar P. Vasopressin and its analogues in shock states: a review. Ann Intensive Care. 2020;10 (1):9. doi:10.1186/s13613-020-0628-2

22. Shi SJ, Li H, Liu M, et al. Mortality prediction to hospitalized patients with influenza pneumonia: $\mathrm{PO} / \mathrm{FiO} 2$ combined lymphocyte count is the answer. Clin Respir J. 2017;11(3):352-360. doi:10.1111/crj.12346

23. Bellelli V, d'Ettorre G, Celani L, Borrazzo C, Ceccarelli G, Venditti M. Clinical significance of lymphocytopenia in patients hospitalized with pneumonia caused by influenza virus. Crit Care. 2019;23(1):330. doi:10.1186/s13054-019-2608-1

24. Boonnak K, Vogel L, Feldmann F, Feldmann H, Legge KL, Subbarao K. Lymphopenia associated with highly virulent $\mathrm{H} 5 \mathrm{~N} 1$ virus infection due to plasmacytoid dendritic cell-mediated apoptosis of T cells. J Immunol. 2014;192(12):5906-5912. doi:10.4049/jimmunol.1302992

25. Fox A, Le NM, Horby P, et al. Severe pandemic H1N1 2009 infection is associated with transient NK and T deficiency and aberrant CD8 responses. PLoS One. 2012;7(2):e31535. doi:10.1371/journal.pone.0031535

26. Gonzalez Y, Juarez E, Carranza C, Sada E, Pedraza-Sanchez S, Torres M. Diminished effector and memory CD8+ circulating $\mathrm{T}$ lymphocytes in patients with severe influenza caused by the AH1N1 pdm09 virus. Virology. 2017;500:139-148. doi:10.1016/j. virol.2016.10.016

27. Chen L, Han X, Li YL, Zhang C, Xing X. FluA-p score: a novel prediction rule for mortality in influenza A-related pneumonia patients. Respir Res. 2020;21(1):109. doi:10.1186/s12931-020-01379-Z

28. Guo L, Wei D, Zhang X, et al. Clinical features predicting mortality risk in patients with viral pneumonia: the MuLBSTA Score. Front Microbiol. 2019;10:2752. doi:10.3389/fmicb.2019.02752

29. Gobolos L, Racz I, Hogan M, et al. The role of renin-angiotensin system activated phagocytes in the SARS-CoV-2 coronavirus infection. $J$ Vasc Surg. 2020:S0741-5214(20)32605-7. doi:10.1016/j.jvs.2020.12.056

30. Gao YL, Du Y, Zhang C, et al. Role of renin-angiotensin system in acute lung injury caused by viral infection. Infect Drug Resist. 2020;13:3715-3725. doi:10.2147/IDR.S265718

31. Huang F, Guo J, Zou Z, et al. Angiotensin II plasma levels are linked to disease severity and predict fatal outcomes in H7N9-infected patients. Nat Commun. 2014;5(1):3595. doi:10.1038/ncomms4595

32. Zou Z, Yan Y, Shu Y, et al. Angiotensin-converting enzyme 2 protects from lethal avian influenza A H5N1 infections. Nat Commun. 2014;5 (1):3594. doi:10.1038/ncomms4594

33. Shimizu T, Iwamoto N, Okamoto M, et al. Scleroderma renal crisis complicated with thrombotic microangiopathy triggered by influenza B virus infection. Intern Med. 2019;58(3):441-445. doi:10.2169/ internalmedicine.1441-18

34. Costopoulos C, Benson A, Prasad S, Ghuran A. Diagnostic dilemmas in cardiology. BMJ Case Rep. 2012;2012:2012. doi:10.1136/bcr-2012006521

35. Lang JP, Wang X, Moura FA, Siddiqi HK, Morrow DA, Bohula EA. A current review of COVID-19 for the cardiovascular specialist. $\mathrm{Am}$ Heart J. 2020;226:29-44. doi:10.1016/j.ahj.2020.04.025

36. Imai Y, Kuba K, Rao S, et al. Angiotensin-converting enzyme 2 protects from severe acute lung failure. Nature. 2005;436 (7047):112-116. doi:10.1038/nature03712

37. Kuba K, Imai Y, Rao S, et al. A crucial role of angiotensin converting enzyme 2 (ACE2) in SARS coronavirus-induced lung injury. Nat Med. 2005;11(8):875-879. doi:10.1038/nm1267

38. Sinagra G, Corra U, Contini M, et al. Choosing among beta-blockers in heart failure patients according to beta-receptors' location and functions in the cardiopulmonary system. Pharmacol Res. 2020;156:104785. doi:10.1016/j.phrs.2020.104785 
39. Levi M, Eerenberg E, Kamphuisen PW. Bleeding risk and reversal strategies for old and new anticoagulants and antiplatelet agents. $J$ Thromb Haemost. 2011;9(9):1705-1712. doi:10.1111/j.15387836.2011.04432.x

40. Muthuri SG, Venkatesan S, Myles PR, et al. Impact of neuraminidase inhibitors on influenza $\mathrm{A}(\mathrm{H} 1 \mathrm{~N} 1)$ pdm09-related pneumonia: an individual participant data meta-analysis. Influenza Other Respir Viruses. 2016;10(3):192-204. doi:10.1111/irv.1 2363
41. Zhou Y, Fu X, Liu X, et al. Use of corticosteroids in influenza-associated acute respiratory distress syndrome and severe pneumonia: a systemic review and meta-analysis. Sci Rep. 2020;10 (1):3044. doi:10.1038/s41598-020-59732-7

42. Cangemi R, Falcone M, Taliani G, et al. Corticosteroid use and incident myocardial infarction in adults hospitalized for community-acquired pneumonia. Ann Am Thorac Soc. 2019;16 (1):91-98. doi:10.1513/AnnalsATS.201806-419OC

\section{Publish your work in this journal}

Infection and Drug Resistance is an international, peer-reviewed openaccess journal that focuses on the optimal treatment of infection (bacterial, fungal and viral) and the development and institution of preventive strategies to minimize the development and spread of resistance. The journal is specifically concerned with the epidemiology of antibiotic resistance and the mechanisms of resistance development and diffusion in both hospitals and the community. The manuscript management system is completely online and includes a very quick and fair peerreview system, which is all easy to use. Visit http://www.dovepress.com/ testimonials.php to read real quotes from published authors. 